\title{
Temperature dependence of ssrA-tag mediated protein degradation
}

\author{
Oliver Purcell ${ }^{*}$, Claire S Grierson², Mario di Bernardo 3,4 and Nigel J Savery ${ }^{5}$
}

\begin{abstract}
Building synthetic gene networks with highly transient dynamics requires rapid protein degradation. We show that the degradation conferred by two commonly used ssrA tags is highly temperature dependent. Synthetic gene networks are being used increasingly in real-world applications where they may be subjected to variable conditions, and be required to display precise, quantitative dynamics, which will be more susceptible to environmental changes than the general qualitative dynamics focussed on so far.
\end{abstract}

\section{Introduction}

Rapid protein degradation is vital for the creation of synthetic gene networks with highly transient dynamics. The standard means of achieving rapid protein degradation in bacterial synthetic gene networks has been through the use of ssrA tags. These are short (usually 11 amino acid) peptide tags added cotranslationally to the $\mathrm{C}$-terminus of a nascent protein, that are recognised by the AAA+ ClpXP and ClpAP host proteases [1] and target the tagged protein for degradation [2,3]. ssrA tags are part of a larger family of degradation tags, or 'degrons', which can be present in both the $\mathrm{N}$ - and $\mathrm{C}$ - terminus of proteins [4]. The ssrA tags are generally referred to by the final three amino acids, for instance the wild-type tag ends in the amino acid sequence LAA and is known as the LAAssrA tag. ssrA tags have been used frequently in synthetic oscillators [5-8].

Synthetic biology is increasingly moving towards realworld applications [9] in which synthetic gene networks will not always be present at favourable laboratory conditions. Networks designed under one set of conditions (growth rate, nutrient supply, temperature etc) will not necessarily function as designed under another set of conditions. Networks must therefore be designed to function correctly, or at least predictably, in sub-optimal and changeable environments. A robustness to temperature variation will need to form part of this, as demonstrated by

\footnotetext{
${ }^{*}$ Correspondence: opurcell@mit.edu

1 MIT Synthetic Biology Center, Massachusetts Institute of Technology, 500

Technology Square, NE47-235, Cambridge, MA 02139 USA

Full list of author information is available at the end of the article
}

the observation of a substantial effect of temperature on a synthetic gene oscillator [6]. It has recently been shown that the bacterial chemotaxis machinery is highly temperature compensated [10]. Therefore a relevant question is whether the bacterial degradation machinery also exhibits a significant level of temperature compensation. This is important not only for synthetic biologists investigating the effects of temperature on gene network performance, but also for those studying the degradation machinery itself.

Here we examine the degradation of LacI, a protein frequently used in bacterial synthetic gene networks [5,6,8,11-13], tagged with either the LAA or LVA ssrA tag. We present results that demonstrate a marked temperature dependence in the degradation rate conferred by both tags.

\section{Results and discussion}

Figure 1 shows the amount of LacI, tagged with either an LAA (LacI-LAA) or LVA (LacI-LVA) ssrA tag, or left untagged, from $E$. coli cells grown at 37 or $25^{\circ} \mathrm{C}$, before the addition of chloramphenicol (used to stop translational elongation) (0 minutes) and at 10, 20, 30, 45 and 60 minutes post addition of chloramphenicol.

LacI carrying an LAA or LVA tag was degraded approximately 3-5 fold faster in cells grown at $37^{\circ} \mathrm{C}$ than in cells grown at $25^{\circ} \mathrm{C}$. The apparent half-life of LacI-LAA increased from $\sim 8$ minutes at $37^{\circ} \mathrm{C}$ to $\sim 38$ minutes at $25^{\circ} \mathrm{C}$ and the apparent half-life of LacI-LVA increased from $\sim 13$ minutes to $\sim 41$ minutes. The stability of untagged LacI was unaffected by temperature, indicating 


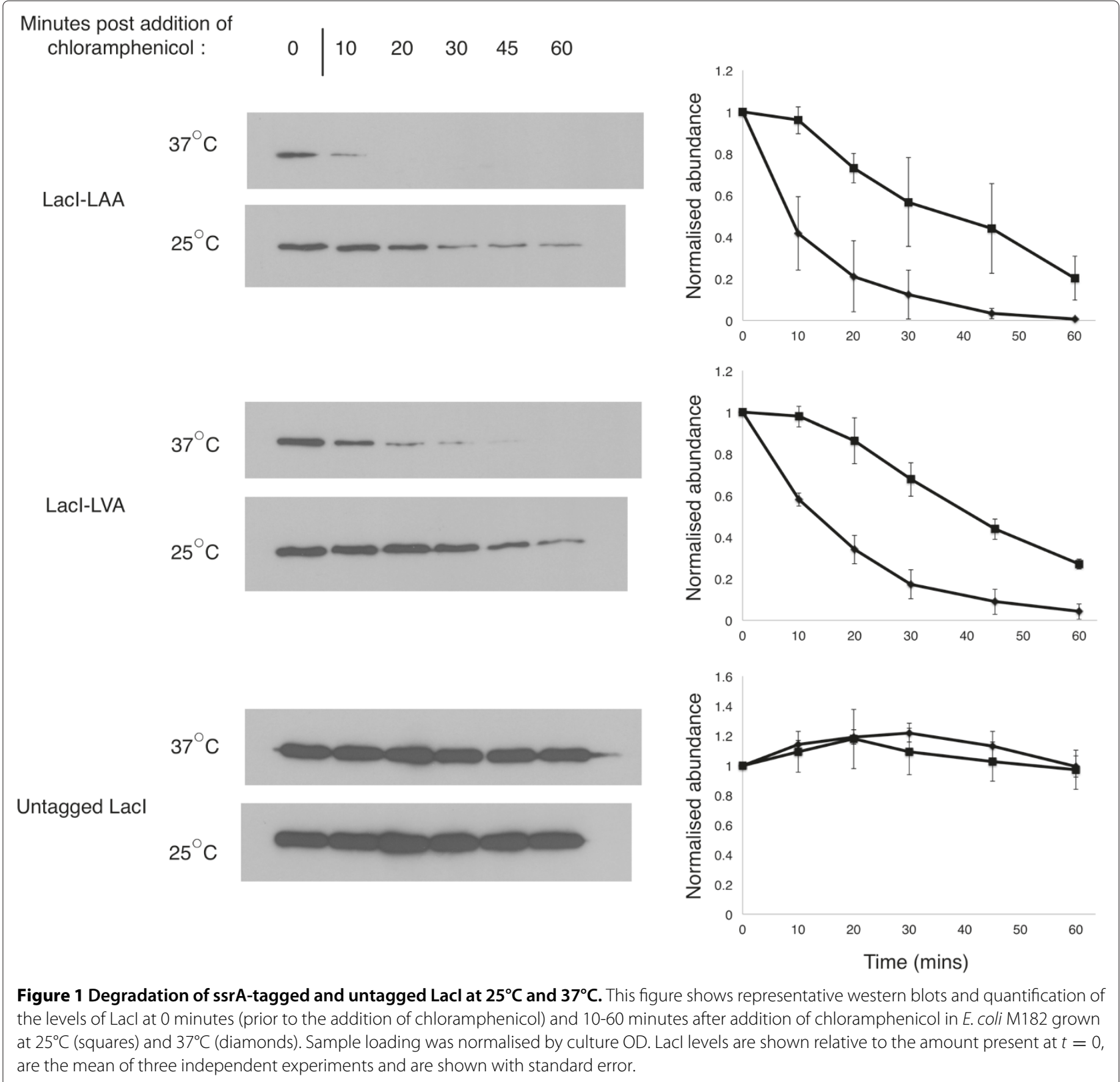

that the observations were dependent on the presence of the ssrA tags.

The result presented here demonstrates that degradation conferred by both LAA and LVA ssrA tags is substantially affected by temperature, and shows that little or no mechanism for temperature compensation exists in this system. Degradation of some tagged cellular proteins has been shown to be temperature dependent [14], but to the best of our knowledge the effect of temperature on the stability of proteins tagged with ssrA tags commonly used within synthetic biology has not been previously investigated. This temperature dependence has been demonstrated for LacI, and there is no reason to assume that it will not extend to other proteins.

This result is potentially important for the future construction of synthetic gene networks in bacteria. Future networks will be increasingly designed for real-world applications where they may need to function over a range of temperatures and conditions. This result highlights a limitation of the current means of tuning protein degradation within bacterial synthetic gene networks and suggests that new, perhaps synthetic, protein degradation pathways that are robust to environmental (and physiological) variations need to be developed. 


\section{Materials and methods}

E. coli strain M182 [15] was transformed with one of three plasmids containing lacI tagged with either an LAA (amino acid sequence: AANDENYALAA. DNA sequence: GCTGCTAACGACGAAAACTACGCTCTGGCTGCT) or LVA (amino acid sequence: AANDENYALVA. DNA sequence: GCTGCAAACGACGAAAACTACGCTTTAGTAGCT) ssrA tag, or left untagged, referred to as pOP_L-LAA, pOP_L-LVA and pOP L-NoTg respectively. The plasmids were constructed by cloning lacI and its two tagged variants into an expression cassette comprising the Prrn promoter and the UO RBS region [16], upstream of the lacI coding region, and the terminator BBa_B0015 [17] downstream. The plasmid backbone was pSB6A1 [18]. Transformed cells were grown overnight on LB agar with ampicillin $(100 \mu \mathrm{g} / \mathrm{ml})$. Colonies were grown in $5 \mathrm{ml}$ of EZ rich media (Teknova, CA) overnight. $0.5 \mathrm{ml}$ of culture was added to $25 \mathrm{ml} \mathrm{EZ} \mathrm{rich} \mathrm{media,} \mathrm{and} \mathrm{grown}$ at both 25 and $37^{\circ} \mathrm{C}$ with shaking $(250 \mathrm{rpm})$ to $\mathrm{OD}_{600}$ of 0.4-0.6. A $1 \mathrm{ml}$ sample was taken, centrifuged at 11,700x g and supernatant removed. The pellet was frozen in liquid nitrogen. Chloramphenicol was added to the cultures to a final concentration of $136 \mu \mathrm{g} / \mathrm{ml} .1 \mathrm{ml}$ samples were taken at subsequent time points of 10, 20, 30, 45 and 60 minutes. The same procedure for the initial time point sample was followed. Samples were stored at $-80^{\circ} \mathrm{C}$.

To assay LacI abundance, SDS loading buffer was added to samples in an amount relative to the OD of the sample. Samples were heated for 3 minutes at $95^{\circ} \mathrm{C}$, before being analysed by SDS-PAGE and western blotting, using a mouse monoclonal antibody against LacI (Abcam) and a goat anti-mouse IgG-HRP conjugated secondary antibody (Santa Cruz Biotechnology). Blots were quantified using ImageJ software.

\section{Authors' contributions}

OP, NJS, CSG and MdB conceived the experiments. OP carried out the experiments. OP and NJS wrote the manuscript. All authors read and approved the final manuscript.

\section{Acknowledgements}

Funding was provided by the Bristol Centre for Complexity Sciences through EPSRC-GB Grant No. EP/E501214/1.

\section{Author Details}

${ }^{1}$ MIT Synthetic Biology Center, Massachusetts Institute of Technology, 500 Technology Square, NE47-235, Cambridge, MA 02139 USA. ${ }^{2}$ School of Biological Sciences, University of Bristol, Bristol BS8 1UG, UK. ${ }^{3}$ Department of Engineering Mathematics, University of Bristol, Bristol BS8 1TR, UK. ${ }^{4}$ Department of Systems and Computer Engineering, University of Naples Federico II, Via Claudio 21, 80125, Napoli, Italy. ${ }^{5}$ School of Biochemistry, University of Bristol, Bristol BS8 1TD, UK.

Received: 10 February 2012 Accepted: 23 July 2012

Published: 23 July 2012

\section{References}

1. Gottesman S: Proteolysis in bacterial regulatory circuits. Annu Rev cell Dev Biol 2003, 19:565-587.
2. Oh BK, Chauhan AK, Isono K, Apirion D: Location of a gene (ssrA) for a small, stable RNA (10Sa RNA) in the Escherichia coli chromosome. Bacteriol 1990, 172(8):4708-4709.

3. McGinness K, Baker T, Sauer R: Engineering controllable protein degradation. Mol Cell 2006, 22:701-707.

4. Flynn JM, Neher SB, Kim YI, Sauer RT, Baker TA: Proteomic discovery of cellular substrates of the ClpXP protease reveals five classes of ClpX-recognition signals. Mol Cell 2003, 11(3):671-683.

5. Mondragón-Palomino O, Danino T, Selimkhanov J, Tsimring L, Hasty J: Entrainment of a population of synthetic genetic oscillators. Science 2011, 333(6047):1315-1319.

6. Stricker J, Cookson S, Bennett MR, Mather WH, Tsimring LS, Hasty J: A fast, robust and tunable synthetic gene oscillator. Nature 2008, 456(7221):516-U39.

7. Fung $\mathrm{E}$, Wong WW, Suen JK, Bulter T, Lee Sg, Liao JC: A synthetic gene-metabolic oscillator. Nature 2005, 435(7038):118-122.

8. Elowitz MB, Leibler $\mathrm{S}$ : A synthetic oscillatory network of transcriptional regulators. Nature 2000, 403(6767):335-338.

9. Khalil AS, Collins JJ: Synthetic biology: applications come of age. Nat Rev Genet 2010, 11(5):367-379.

10. Oleksiuk O, Jakovljevic V, Vladimirov N, Carvalho R, Paster E, Ryu WS, Meir $Y$, Wingreen NS, Kollmann M, Sourjik V: Thermal Robustness of Signaling in Bacterial Chemotaxis. Cell 2011, 145(2):312-321.

11. Gardner TS, Cantor CR, Collins JJ: Construction of a genetic toggle switch in Escherichia coli. Nature 2000, 403(6767):339-342.

12. Lou C, Liu X, Ni M, Huang $Y$, Huang Q, Huang L, Jiang L, Lu D, Wang $M$, Liu C, Chen D, Chen C, Chen X, Yang L, Ma H, Chen J, Ouyang Q: Synthesizing a novel genetic sequential logic circuit: a push-on push-off switch. Mol Syst Biol 2010, 6:350.

13. Basu S, Gerchman Y, Collins CH, Arnold FH, Weiss R: A synthetic multicellular system for programmed pattern formation. Nature 2005, 434(7037):1130-1134.

14. Herman C, Thévenet D, Bouloc P, Walker GC, D'Ari R: Degradation of carboxy-terminal-tagged cytoplasmic proteins by the Escherichia coli protease HflB (FtsH). Genes \& development 1998, 12(9):1348-1355.

15. Casadaban M, Cohen S: Analysis of gene control signals by DNA fusion and cloning in Escherichia coli. J Mol Biol 1980, 138(2):179-207.

16. Neupert J, Karcher D, Bock R: Design of simple synthetic RNA thermometers for temperature-controlled gene expression in Escherichia coli. Nucleic Acids Res 2008, 36(19):e124.

17. BBa_B0015 registry information (MIT parts registry) [http:// partsregistry.org/Part:BBa_B0015].

18. pSB6A1 registry information (MIT parts registry) [http://partsregistry. org/Part:pSB6A1]

doi:10.1186/1754-1611-6-10

Cite this article as: Purcell et al:: Temperature dependence of ssrA-tag mediated protein degradation. Journal of Biological Engineering 2012 6:10.
Submit your next manuscript to BioMed Central and take full advantage of:

- Convenient online submission

- Thorough peer review

- No space constraints or color figure charges

- Immediate publication on acceptance

- Inclusion in PubMed, CAS, Scopus and Google Scholar

- Research which is freely available for redistribution
BioMed Central 